arguments about Nazi prudery must thus be seen, she insists, as articulating an antipostfascist critique. Quite unselfconsciously, the New Left was reacting only to the sexual mores that their parents had adopted since the collapse of Nazism in 1945. They neither explored nor even really wished to know the details about what sex had looked like under fascism. The Holocaust was invoked as a means of reinforcing the point, sometimes at the risk of extreme insensitivity to its victims. These insensitivities were displayed not only by Christians who compared abortion to the Holocaust, but also by feminists whose justified struggles with their erstwhile colleagues in the New Left often involved the argument that women had been among the primary victims of Nazism.

Herzog's dismantling of the New Left's argument is utterly convincing and eloquently written. Her critique is simultaneously fair-minded and unrelentingly critical of all sides of the debate. Eschewing all temptations to simplify, she skewers the hypocrisy of both camps, while remaining appreciative of the humane and progressive impulses in the New Left and the diversity of views, strength of conviction and ultimate pragmatism of Christian commentators. She reinforces her point about the complexity and political nature of memory and its relationship to sexuality in a chapter on the GDR that emphasizes how a more future-oriented, less commercialized, less sexist and less overtly politicized approach to sexuality was consciously integrated into state legitimization projects, and the personal life stories and memories of East German citizens. Even in this chapter, Herzog's source base includes a wide diversity of scholarly and popular literature with few archival sources. This is both a strength and a weakness. Post-World War II German society is described for us in vivid and convincing detail, and groups with cultural clout but little formal political power are appropriately credited with motivating massive shifts in public opinion. The integration of more archival sources might have provided insight into how these cultural transformations were translated into shifts in law and policy. But this is a quibble. Sex after Fascism is path-breaking and field-defining. No specialist in the history of sexuality should ignore it.

doi:10.1057/fr.2008.11

Annette F. Timm

\title{
Transforming masculinities: men, cultures, bodies, power, sex and love
}

V.J. Seidler; Routledge, London, 2005, 176p, ISBN 0415370744, £21.99

Transforming Masculinities is presented as a multidisciplinary text, which critically explores the ways in which men and masculinities are commonly 
theorized. Within the preface Seidler presents a number of objectives for this book, including examination of the theoretical tenets that underpin the study of contemporary masculinities. It is asserted that in the West, white European masculinity has dominated and reinforced a rationalist tradition. Seidler contends that formulating new questions and theoretical explorations will involve acknowledging the 'difficulties of translation across cultural worlds as well as personal and theoretical exploration that can open up issues of bodies, desires and sexualities' ( $p$. xxiii). These aims of exploring cultural traditions that have influenced the discourse of masculinities across cultures, the need to listen to men, and challenging the notion of power as a dominant discourse within theorizations of masculinity become prominent themes throughout the book.

The chapters are wide reaching and explore a number of contemporary issues such as: cultures and differences; power and social movements; male violence; gender and sexed identities; and fatherhood. Within each chapter Seidler offers his own theoretical perspective, and uses a backdrop of authors to underpin his critique of current theorizations. For example, in Chapter 2 the cultural influence and historical significance of religion and how this has influenced the development of masculinity is discussed in some depth. In Chapter 4 we are asked to rethink male violence, and contrasting experiences from Europe and Central America are used to illuminate the discussion which challenges men's social power within a patriarchal society and its application across cultures. While Seidler's critique of current thinking is welcomed, his belief that theorization of masculinities is 'universal' or applied universally is questionable.

At times the discussion can be so fast moving that the sequence of the narrative becomes confusing to the reader and the themes within some chapters lost. The book's opaqueness is in part due to the omission of a unifying theme or thread, and an incoherent structure within some sections. The lack of introductory and summary paragraphs within chapters mean their objectives and the points the author is trying to make are often unclear. For example, Chapter 10 (entitled 'Memories, Bodies and Hidden Injuries') moves erratically and without explanation from a discussion of father's silences surrounding war to the control of the male body to drug culture.

The Contents page indicates that the work addresses a diverse range of topics regarding the negotiation of masculine identity in relation to its dominant discourse (which, incidentally, is taken as a given as the author does not state where, how, or why this discourse is produced or maintained as dominant). However, we were disappointed that a number of the issues raised were conventional and tired - for example, that anti-gay behaviour is a strategy to assuage anxieties about one's own sexuality and sexual identity (Chapter 7), and that men often repress displays of emotion so as not to compromise their male identity (Chapter 11). 
The back cover of the book states that it is 'written in a practical, versatile manner' but we found its authoritative style to be sometimes patronizing. The reader is faced with many bald and unsubstantiated claims (e.g. 'increasingly boys are also translating emotional issues they have into food and body-image problems' ( $p .86$ ) and 'in middle-class families there is often considerable emotional distance between fathers and children' ( $p$. 94) which lack any form of verification or support).

We were hoping that the Conclusion would provide a clear summation and thus clarify the author's arguments and intentions, but unfortunately it is incoherent, consisting of un/semi-connected theoretical paradigms and assumptions which left us rather disoriented.

Overall, this is an interesting text, which does challenge some aspects of the theoretical discourse within masculinities. However, illumination of the issues raised using empirical research would have provided a more engaging read. Also, as much time is spent in critique of major theories/theorists with little background information, this book would be more suited to readers who have already familiarized themselves with the major texts and arguments within this area.

doi: $10.1057 / \mathrm{fr} .2008 .17$

\section{Dave Clarke and Richard Taulke-Johnson}

\section{American Sweethearts: Teenage Girls in Twentieth- Century Popular Culture}

Ilana Nash; Indiana University Press, Bloomington, 2006, viiip + 264p, ISBN 0-253-21802-0, $£ 14.95$ (Pbk)

American Sweethearts: Teenage Girls in Twentieth-Century Popular Culture provides a lucid cultural history of the teenage girl in American popular culture from the 1930s to the 1960s. Examining such figures as Nancy Drew, Judy Graves, Corliss Archer, Patty Duke and Gidget, Ilana Nash's fascinating study anatomizes portrayals of adolescent femininity in and across mainstream media - including books, magazines, films, television and theatre. The term 'narrative cycle' is used here to describe 'a collection of stories about a single character across several media' ( $p .5)$. This definition enables Nash to draw a critical distinction between 'narrative cycles' as reiterations of a character across different narrative forms (resulting from its popularity among consumers) and 'franchises', which 'introduce new characters with the intention of exploiting their brand simultaneously in several different markets' (p. 5). The study focuses on comic narrative cycles because, unlike dramas of the period, they bring into focus 